\title{
Serum complement levels as prognostic marker for monitoring treatment response in lupus nephritis
}

\author{
Khan SBa ${ }^{a}$, Islam RN ${ }^{b}$, Mizan MSB ${ }^{c}$, Rahman AKMS $^{d}$, Hossain SMZd, Mullah $\mathbf{S}^{\mathbf{e}}$, \\ Ershad SM ${ }^{f}$, Rahman Tg, Rahman MM $^{\mathrm{h}}$, Feroz $\mathrm{S}^{\mathrm{i}}$, Kaiser $\mathrm{AM}^{\mathrm{j}}$
}

\begin{abstract}
Background: Lupus nephritis (LN) is one of the most common and serious manifestations of systemic lupus erythematosus (SLE) that causes significant morbidity and mortality. Certain biomarkers for LN are sometimes able to assess treatment response in lupus nephritis. This study aimed to compare serum complement levels (C3 and $C 4$ ) as markers of treatment response of $L N$ and their relation to the $L N$ class in renal biopsy.

Methods: This prospective observational study was conducted in the Department of Nephrology, Bangabandhu Sheikh Mujib Medical University (BSMMU), Dhaka, Bangladesh from July 2018 to August 2019. Twenty seven patients who were diagnosed with LN after kidney biopsy were included in this study. Serum complement levels (C3 and C4), 24 hours urinary total protein (24-hr UTP) and anti-double-stranded DNA (anti-ds DNA) were measured in all patients at baseline, 3 months and 6 months after treatment initiation. These biomarker values before and after treatment were compared between the proliferative and non-proliferative LN patients.

Results: Serum C3 levels were significantly different between patients with proliferative LN (Class III and Class IV) and non-proliferative LN (Class V) at baseline (0.47 $\pm 0.32 \mathrm{~g} / \mathrm{l}$ versus $0.89 \pm 0.43 \mathrm{~g} / \mathrm{l}, \mathrm{p}=0.009)$ and levels changed significantly 6 months after treatment initiation $(p<0.001)$ and likewise for serum C4 levels $(0.10 \pm 0.06$ $\mathrm{g} / \mathrm{l}$ versus $0.24 \pm 0.26 \mathrm{~g} / \mathrm{l}, \mathrm{p}=0.040)$. The values of 24 - $h r \mathrm{UTP}$ and anti-ds-DNA were significantly different 6 months after treatment with p value $<0.05$ in both groups but $C 3(p<0.001)$ and renal Systemic Lupus Erythematosus Disease Activity Index ( $r S L E D A I)(p<0.001)$ were only significant in the proliferative group. On the other hand, after 6 months treatment, C4 levels became relatively higher but that was not significant in both groups ( $p>0.05)$.

Conclusion: After 6 months of treatment, serum C3 and C4 levels increased towards normal in both LN groups. Serum C3 and C4 levels in patients with LN correlate with disease activity. Therefore, serum complement (C3 and C4) levels may be utilized as serological biomarkers for treatment response of LN.
\end{abstract}

Key words: lupus nephritis, serum complements, systemic lupus erythematosus.

(BIRDEM Med J 2021; 11(2): 97-102)

\footnotetext{
Author information

a. Saiful Bahar Khan, Assistant Professor, Department of Nephrology, Ad-din Women's Medical College Hospital, Dhaka, Bangladesh.

b. Rafi Nazrul Islam, Senior Medical Officer, Department of Nephrology \& Dialysis, BIRDEM General Hospital, Dhaka, Bangladesh.

c. Md. Saif Bin Mizan, Assistant Professor, Department of Nephrology, Dr. Sirajul Islam Medical College, Dhaka, Bangladesh.

d. A.K.M. Shahidur Rahman, Shah Md. Zakir Hossain, Medical Officer, Department of Nephrology, Bangabandhu Sheikh Mujib Medical University (BSMMU), Dhaka, Bangladesh.

e. Shahida Mullah, Junior Consultant, Department of Medicine, Sarkari Karmachari Hospital, Dhaka, Bangladesh.

f. Sk. Md. Ershad, Registrar, Department of Nephrology, National Institute of Kidney Diseases \& Urology, Dhaka, Bangladesh.

g. Tanvir Rahman, Specialist, Department of Nephrology, United Hospital Limited, Dhaka, Bangladesh.

h. Md. Mustafizur Rahman, Assistant Professor, Department of Nephrology, Sheikh Hasina Medical College, Tangail, Bangladesh.

i. Salahuddin Feroz, Junior Consultant (Nephrology), Sheikh Hasina National Institute of Burn and Plastic Surgery, Dhaka, Bangladesh.

j. Amir Mohammad Kaiser, Assistant Professor, Department of Nephrology \& Dialysis, Gonoshaystha Somazvittik Medical College and Gonoshaystha Nagar Hospital, Dhaka, Bangladesh.
}

Address of correspondence: Saiful Bahar Khan, Assistant Professor, Department of Nephrology, Ad-din Women's Medical College Hospital, Dhaka, Bangladesh. Email: drsbkhan.edu@gmail.com

Received: September 10, 2020

Revision received: January 28, 2021

Accepted: February 28, 2021 


\section{INTRODUCTION}

Systemic Lupus Erythematosus (SLE) is an autoimmune disease which affects almost every system in the body with different degrees of severity. ${ }^{1}$ The clinical features of this chronic disease may vary from person to person; ranging from mild joint pain and skin involvement to severe, life-threatening internal organ damage., ${ }^{2,3}$ Renal involvement in SLE termed as lupus nephritis (LN) is one of the most common manifestations of SLE and continues to be a major contributor to morbidity and mortality. ${ }^{4}$ The pathogenesis of $\mathrm{LN}$ is a complicated process; including glomerular deposition of autoantibodies, complement activation, cellular proliferation, release of chemokines and proinflammatory cytokines leading to inflammation and fibrosis. ${ }^{5,6,7}$

Up to $50 \%$ of SLE patients will have clinically evident kidney disease at presentation; during follow-up, renal involvement will occur in $60 \%$ of patients. ${ }^{8}$ Clinical course ranges from asymptomatic urinary occult blood to nephrotic syndrome or acute kidney injury since kidney injuries in LN are so variable. ${ }^{9}$

All four renal compartments glomeruli, tubules, interstitium and blood vessels may be affected in LN. ${ }^{10}$ In addition, if LN develops early in the course of SLE, it becomes a major predictor of poor prognosis. ${ }^{11}$ It has been reported that, in spite of remarkable progression in treatment, up to $25 \%$ of SLE patients progress to endstage renal failure (ESRD) 10 years after the onset of renal damage and the 5-year survival of nephritis patients is $82 \%$, whereas 5 -year survival for those without nephritis is $92 \% .10,12,13$

Despite the fact that several efficacious therapies have been used to treat lupus nephritis, the incidence of ESRD from LN increased day by day. This may reflect the limitations of our current treatment options, poor access to health care, late diagnosis, delay in treatment and lack of follow-up the response of treatment. ${ }^{14}$ Earlier treatment has a beneficial effect on the prognosis of LN and it has been shown that late diagnosis of $\mathrm{LN}$ is correlated with a higher frequency of renal insufficiency. ${ }^{14,15}$ Moreover, delayed diagnosis is associated with an increased incidence of ESRD. ${ }^{15}$

Certain laboratory markers which may be used for assessment of $\mathrm{LN}$ are proteinuria, urine protein creatinine ratio (PCR), creatinine clearance, anti-double-stranded DNA (anti-dsDNA) antibodies, and complement levels. ${ }^{16}$ It was observed, however, that these parameters, namely anti-dsDNA antibodies, complement levels, proteinuria, creatinine clearance and urinary sediment are not specific enough to detect disease activity in renal involvement and nephritis relapse. ${ }^{17}$ Anti-dsDNA antibodies are necessary but not sufficient for the development of LN exacerbations. ${ }^{18}$

Anti-dsDNA antibody assays can be negative early in disease, after treatment or when the patient is in clinical remission; therefore, not all patients with SLE are seropositive at any one time. ${ }^{19}$ However, these traditional markers are often not as specific as desired in situations of diagnostic dilemma. ${ }^{16}$ Repeat kidney biopsy, though useful, is an invasive procedure with its own complications. ${ }^{5}$ Previous reports have demonstrated that focal, diffuse proliferative and membranous nephritides (World Health Organization LN classes III, IV, V) have poor prognosis, especially class IV LN and they usually require active interventions to inhibit their progression to renal failure. ${ }^{20}$

To date, studies have produced controversial reports regarding correlation of serum $\mathrm{C} 3$ and $\mathrm{C} 4$ levels in such patients with renal disease activity and prognosis. ${ }^{20}$ Assessment of response to treatment using proteinuria as the sole biomarker has also not correlated well with renal functional recovery. Systemic Lupus Erythematosus Disease Activity Index (SLEDAI) is a global index that stratifies severity of SLE. ${ }^{21}$ The renal SLEDAI (rSLEDAI) score consists of the four kidneyrelated parameters: hematuria, pyuria, proteinuria, and urinary casts. ${ }^{21}$ Each parameter consists of 4 point. Scores for the rSLEDAI can range from 0 (inactive renal disease) to a maximum of 16 . Active lupus nephritis was those with an rSLEDAI score of 4 or more. This study aims to compare serum complement levels ( $\mathrm{C} 3 \& \mathrm{C} 4)$ as markers of treatment response of $\mathrm{LN}$ and their relation to the $\mathrm{LN}$ classes.

\section{METHODS}

This prospective observational study was conducted in the Department of Nephrology and Department of Rheumatology, Bangabandhu Sheikh Mujib Medical University (BSMMU), Dhaka, Bangladesh from July 2018 to August 2019 among 27 patients, who were diagnosed with LN after kidney biopsy. The study was approved by the Ethical Review Committee, BSMMU, Dhaka, Bangladesh. Informed written consent from the participants was obtained prior to the enrollment in the study. 
Adult SLE patients, diagnosed as LN admitted in the Nephrology department with urinary total protein $>0.5$ gm were included in this study. Pregnant women and lactating mothers, patients with malignancy, patients with active infection, patients with autoimmune disease other than SLE and ESRD patients were excluded from the study.

The renal histology was classified according to the International Society of Nephrology/Renal Pathology Society. ${ }^{22}$ According to the abbreviated version of the classification; combined classes III/V or IV/V were considered as class III or IV, respectively. Out of those patients who were class III, IV and V LN diagnosed histologically without any features of exclusion criteria and willing to participate in this study were finally enrolled for this study. rSLEDAI was used to assess kidney disease activity. ${ }^{21}$

Before starting the treatment base line levels of complete blood count (CBC), Erythrocyte sedimentation rate (ESR), C-reactive protein (CRP), urine routine microscopic examination (urine- $\mathrm{R} / \mathrm{M} / \mathrm{E}$ ), 24-hour urinary total protein (24-hr UTP), serum creatinine, serum electrolytes, serum alanine aminotransferase (ALT), antinuclear antibody (ANA), serum anti-dsDNA antibody and serum levels of complement components 3 and $4(\mathrm{C} 3 \& \mathrm{C} 4)$ were measured in study patients. After initiation of treatment, CBC, ESR, urine R/M/E, 24-hr UTP, serum creatinine, antidsDNA and serum levels of $\mathrm{C} 3 \& \mathrm{C} 4$ were again measured at 3rd month and 6th month. Each study patient received either intravenous cyclophosphamide (NIH protocol ${ }^{23}$ ) or mycophenolate mofetil (MMF -2 $\mathrm{gm} / \mathrm{day}^{24}$ ) as induction therapy for 6 months.

\section{Statistical analysis}

Statistical analyses were performed by using windows based computer software with Statistical Packages for
Social Sciences (SPSS) version-23 (Armonk, NY: IBM Corp). Level of significance was examined by paired ' $t$ 'test, unpaired 't'-test and Chi-square test. For all statistical tests, we considered $\mathrm{p}$ value $<0.05$ as statistically significant.

\section{RESULTS}

A total of 27 patients were evaluated over the study period. Majority of the study patients $(44.4 \%)$ were in the age group of $21-30$ years. Females were predominant to males (24 versus 3 ) and most patients were in class IV group [13 (48.1\%)] [Table I]. Table II shows urine routine microscopic examination (RME) findings of 27 lupus nephritis patients at baseline, after 3 months and after 6 months. Table III shows urine abnormalities at baseline according to different classes of lupus nephritis.

Table I Baseline characteristics of the study subjects $(\mathrm{N}=27)$

\begin{tabular}{lcc}
\hline & Frequency & Percentage \\
\hline Age & & \\
$\quad<20$ & 8 & 29.6 \\
$\quad 21-30$ & 12 & 44.4 \\
$\quad>30$ & 7 & 25.9 \\
Gender & & \\
$\quad$ Male & 3 & 11.1 \\
$\quad$ Female & 24 & 88.9 \\
ISN/RPS classification & & \\
Class III & 5 & 18.5 \\
Class IV & 13 & 48.1 \\
Class V & 9 & 33.3 \\
\hline
\end{tabular}

Table II Urine R/M/E of the study subjects at baseline, after 3 months and 6 months of treatment

\begin{tabular}{lccc}
\hline & Baseline & After 3 months & After 6 months \\
\hline Mean Pus cells (per HPF) \pm SD & $13.74 \pm 15.38$ & $5.62 \pm 5.73$ & $3.37 \pm 1.33$ \\
Mean RBC (cells per HPF) \pm SD & $41.07 \pm 51.49$ & $4.29 \pm 7.22$ & $2.11 \pm 3.60$ \\
Patients with Casts, n (\%) & $6(22.2 \%)$ & Nil & Nil \\
Patients with proteinuria, & $16(59.3 \%), 3+$ & $15(55.5 \%), 2+$ & $11(40.7 \%), 1+$ \\
n (\%), amount of proteinuria & $11(40.7 \%), 2+$ & $12(44.5 \%), 1+$ & $16(59.3 \%)$, trace \\
\hline
\end{tabular}

SD: Standard deviation, R/M/E: Routine microscopic examination, HPF: High power field. 
Table III Urine abnormalities at baseline according to classes of lupus nephritis

\begin{tabular}{llcccc}
\hline & & Class III & Class IV & Class V & p-value \\
\hline Proteinuria (24-hour UTP) & $500 \mathrm{mg} /$ day -3 gm/day & $4(80.0)$ & $7(53.8)$ & $0(0.0)$ & 0.006 \\
& $>3$ gm/day & $1(20.0)$ & $6(46.2)$ & $9(100.0)$ & 0.001 \\
RBC & $>5 / \mathrm{HPF}$ & $5(100.0)$ & $13(100.0)$ & $2(22.2)$ & 0.001 \\
& $<5 / \mathrm{HPF}$ & $0(0.0)$ & $0(0.0)$ & $7(77.8)$ & 0.001 \\
\hline
\end{tabular}

UTP: Urinary total protein, HPF: High power field. Chi-square test was performed to examine the level of significance

Table IV Laboratory parameters of the study subjects at baseline

\begin{tabular}{lccc}
\hline Parameters & Proliferative (class III+IV) $\mathrm{n}=18$ & Non-proliferative (class V) $\mathrm{n}=9$ & $\mathrm{p}$-value \\
\hline $\mathrm{C} 3(\mathrm{~g} / \mathrm{l})$ & $0.47 \pm 0.32$ & $0.89 \pm 0.43$ & 0.009 \\
$\mathrm{C} 4(\mathrm{~g} / \mathrm{l})$ & $0.10 \pm 0.06$ & $0.24 \pm 0.26$ & 0.040 \\
24-hr UTP (gm/day) & $2.84 \pm 1.00$ & $5.07 \pm 2.06$ & 0.001 \\
S. Creatinine (mg/dl) & $1.15 \pm 0.37$ & $0.86 \pm 0.15$ & 0.036 \\
Anti ds DNA & $162.45 \pm 146.00$ & $95.83 \pm 74.31$ & 0.212 \\
Renal SLEDAI & $12.22 \pm 3.21$ & $5.33 \pm 2.83$ & $<0.001$ \\
SLEDAI & $21.33 \pm 4.34$ & $10.44 \pm 5.64$ & $<0.001$ \\
\hline
\end{tabular}

Unpaired ' $t$ ' -test was done to examine the level of significance

Table V Biomarkers at baseline and after 6 months in proliferative and non-proliferative patients

Proliferative Non-Proliferative $($ Class III+IV) $\mathrm{n}=18 \quad($ Class V) $\mathrm{n}=9$

\begin{tabular}{lcc}
\hline 24-hrUTP & & \\
Baseline & $2.84 \pm 1.00$ & $5.07 \pm 2.06$ \\
After 6 months & $1.53 \pm 1.50$ & $1.37 \pm 1.12$ \\
\% change & $46.12 \pm 47.94$ & $72.89 \pm 24.76$ \\
p-value & 0.003 & $<0.001$ \\
Anti ds DNA & & \\
Baseline & $162.45 \pm 146.00$ & $95.83 \pm 74.31$ \\
After 6 months & $68.90 \pm 73.54$ & $33.32 \pm 33.28$ \\
\% change & $41.78 \pm 42.05$ & $48.17 \pm 33.72$ \\
p-value & 0.002 & 0.031 \\
C3 & & \\
Baseline & $0.47 \pm 0.32$ & $0.89 \pm 0.43$ \\
After 6 months & $0.85 \pm 0.22$ & $0.99 \pm 0.18$ \\
\% change & $-129.46 \pm 101.66$ & $-29.43 \pm 48.11$ \\
p-value & $<0.001$ & 0.385 \\
C4 & & \\
Baseline & $0.10 \pm 0.06$ & $0.24 \pm 0.26$ \\
After 6 months & $0.31 \pm 0.58$ & $0.44 \pm 0.81$ \\
\% change & $-339.74 \pm 976.55$ & $-139.04 \pm 236.71$ \\
p-value & 0.141 & 0.476 \\
rSLEDAI & & \\
Baseline & $12.22 \pm 3.21$ & $5.33 \pm 2.83$ \\
After 6 months & $4.22 \pm 3.99$ & $3.11 \pm 1.76$ \\
\% change & $64.81 \pm 31.26$ & $35.19 \pm 44.45$ \\
p-value & $<0.001$ & 0.051 \\
\hline
\end{tabular}

Paired ' $t$ ' -test was performed to examine the level of significance
Table IV shows laboratory parameters of the study subjects at baseline. At baseline Serum C3 $(p=0.009)$ and $\mathrm{C} 4(\mathrm{p}=0.040)$ levels were significantly lower and 24 hr UTP was significantly higher $(\mathrm{p}=<0.001)$ in membranous/non-proliferative lupus nephritis (class V) then proliferative lupus nephritis (class III+IV).

Table $\mathrm{V}$ shows pre-treatment (at baseline) and posttreatment (after 6 months) value of different parameters in proliferative (Class III \& Class IV) and nonproliferative/membranous (Class V) lupus nephritis. The values of 24-hr UTP and Anti ds DNA were significantly different before and after (6 months) treatment with $\mathrm{p}$ value $<0.05$ in both groups but $\mathrm{C} 3(\mathrm{p}<0.001)$ and rSLEDAI $(p<0.001)$ were only significant in the proliferative group. On the other hand, $\mathrm{C} 4$ levels were became relatively higher (improved) after treatment but that was not significant in both groups ( $\mathrm{p}>0.05)$.

\section{DISCUSSION}

$\mathrm{LN}$ is an immune-mediated glomerulonephritis that is a common consequence in patients with SLE. SLE is an autoimmune disorder caused by loss of tolerance to self-antigens, the production of autoantibodies and deposition of complement-fixing immune complexes (ICs) in injured tissues. Complement is centrally involved and plays key roles in the pathogenesis of SLE; the complement system consists of three pathways and is 
tightly controlled by a set of regulatory proteins to prevent injudicious complement activation on host tissues. The involvement of the complement system in the pathogenesis of SLE is well accepted. ${ }^{25}$

In this study it was observed that most of the study subjects (88.9\%) were females and maximum (44.4\%) were in the age group of $21-30$ years. These findings were consistent with previous studies. ${ }^{24,26,27}$ This can be explained by the fact that lupus nephritis is more common in young females.

Renal biopsy was done in all study patients. Among 27 lupus nephritis patients, the most common histopathological type was class IV (48.1\%) followed by class V (33.3\%) and class III (18.5\%). Near similar findings were observed in a study done by Sharma et al. ${ }^{28}$ where the most common histopathological type was class IV $(50 \%)$, followed by class III $(17.6 \%)$ and class V (9\%) and in another study by Gupta et al..$^{5}$ where proliferative glomerulonephritis (class III and IV) was detected in $31(68.8 \%)$ patients and class II and class V LN was detected in seven (15.5\%) patients each. In both study, number of class V LN patient was less than class III probably due to two factors. Firstly, in both studies all classes of LN patients were included and secondly, combined class (III + V) and class (IV + V) LN patient was more in both groups.

In our study serum complement ( $\mathrm{C} 3$ and $\mathrm{C} 4)$ levels were found to have improved (become higher) in both proliferative and non-proliferative LN groups from baseline to 6 months post treatment initiation, although not significantly always. Similar findings were observed in a study done by Davas et al. ${ }^{29}$ where 19 patients from LN group were assessed at presentation and 6 months after treatment. Another study done by Gupta et al., ${ }^{5}$ they recruited $45 \mathrm{LN}$ patients and 6 months after treatment similar results were observed. The same results we found for 24-hr UTP, anti-dsDNA in both group but $\mathrm{C} 3$ and rSLEDAI decreased significantly in only proliferative group, while no significant difference was found for $\mathrm{C} 4$ levels in both groups. The findings of this current study were consistent with similar previous studies. ${ }^{5,29}$

Several published studies have evaluated several serologic markers for LN. Decreased levels of C 3 and $\mathrm{C} 4$, elevated anti-ds DNA and increased proteinuria have been found to correlate with worsening disease activity. Our study produced similar findings in concert with these previous studies. ${ }^{24,26-29}$ From the above results it seems clear that serum complement ( $\mathrm{C} 3$ and $\mathrm{C} 4)$ levels are reliable markers of disease activity in patients with LN. Further studies will be warranted to elucidate this issue.

\section{Conclusion}

This study permits to conclude that serum complement (C3 and C4) levels in patients with LN correlate with disease activity. After 6 months of treatment serum complement levels increased towards normal in both proliferative and non-proliferative lupus nephritis groups. Serum C3 and C4 may be used as tools to detect disease severity and to monitor treatment response in LN.

\section{Limitation}

It was a single centre study with a relatively small sample size.

\section{Recommendation}

A multi-center prospective study with large sample size should be done to compare other biomarkers as a marker of treatment response of $\mathrm{LN}$ and their relation to the $\mathrm{LN}$ classes.

Authors' contribution: Khan SB studied the design. Khan SB,Islam RN and Mizan MSB analyzed and interpreted the patient data. Hossain SMZ,Mullah S, Ershad SM, Rahman T, Rahman MM, Feroz S and Kaiser AM screened subjects and collected patient data. Khan $\mathrm{SB}$, Islam RN and Rahman AKMS were the major contributor in writing the manuscript. Khan SB and Islam $\mathrm{RN}$ designed the study and helped to revise the manuscript. All authors read and approved the final manuscript.

Conflicts of interest: Nothing to declare.

\section{REFERENCES}

1. Gurevitz SL, Snyder JA, Wessel EK, Frey J, Williamson BA. Systemic lupus erythematosus: a review of the disease and treatment options. Consult Pharm 2013;28(2): $110-21$.

2. Longo DL, Fauci AS, Kasper DL, Hauser SL, Jameson JL, Loscalzo J. Systemic Lupus Erythematosus. In: Harrison's Principles of Internal Medicine.18th ed. New York: McGraw-Hill; 2012. p319-21 
3. Yazdany J, Dall'Era M. Definition and classification of lupus and lupus-related disorders. In: Wallace D, Hahn B, editors. Dubois' Lupus Erythematosus and Related Syndromes. 9th ed. Elsevier; 2018. p15-22

4. Reyes-Thomas J, Blanco I, Putterman C. Urinary Biomarkers in Lupus Nephritis. Clin Rev Allergy \& Immunol 2010;40(3):138-150.

5. Gupta R, Yadav A, Misra R, Aggarwal A. Urinary sCD25 as a biomarker of lupus nephritis disease activity. Lupus 2015;24(3): 273-9.

6. Mavragani C, Fragoulis G, Somarakis G, Drosos A, Tzioufas A, Moutsopoulos H. Clinical and Laboratory Predictors of Distinct Histopathogical Features of Lupus Nephritis. Medicine 2015;94(21):829-36.

7. Wu M, Yang J, Li X, Chen J. The Role of ${ }^{{ }^{\prime}}$ T Cells in Systemic Lupus Erythematosus. J Immunol Res 2016:18.

8. Bomback AS, Appel GB. Updates on the treatment of lupus nephritis. J Am Soc Nephrol 2010;21(12): 202835.

9. Iwata Y, Furuichi K, Kaneko S, Wada T. The Role of Cytokine in the Lupus Nephritis. J Biomed Biotechnol 2011:1-7.

10. Mok C. Biomarkers for Lupus Nephritis: A Critical Appraisal. J Biomed Biotechnol 2010:1-11.

11. Anaya JM, Cañas C, Mantilla RD, Pineda-Tamayo R, Tobón GJ, Herrera-Diaz C, et al. Lupus nephritis in Colombians: contrasts and comparisons with other populations. Clin Rev Allergy \& Immunol 2011;40(3):199-207.

12. Cameron JS. Lupus nephritis. J Am Soc Nephrol 1999;10(2):413-24.

13. de Zubiria-Salgado A, Herrera-Diaz C. Lupus Nephritis: An Overview of Recent Findings. Autoimmune Dis 2012:1-21.

14. Ward MM. Prevalence of physician-diagnosed systemic lupus erythematosus in the United States: results from the third national health and nutrition examination survey. J Womens Health 2004;13(6):713-8.

15. Faurschou M, Starklint H, Halberg P, Jacobsen S. Prognostic factors in lupus nephritis: diagnostic and therapeutic delay increases the risk of terminal renal failure. J Rheumatol 2006;33(8):1563-9.

16. Bertsias GK, Tektonidou M, Amoura Z, Aringer M, Bajema I, Berden JH, et al. Joint European League Against Rheumatism and European Renal Association-European Dialysis and Transplant Association (EULAR/ERAEDTA) recommendations for the management of adult and paediatric lupus nephritis. Ann Rheum Dis 2012 Nov 1; 71(11): 1771-82.
17. Rovin BH, Zhang X. Biomarkers for lupus nephritis: the quest continues. J Am Soc Nephrol 2009;4(11):1858-65.

18. •ivkovi V, Stankovi A, Cvetkovi T, Miti B, Kosti S, Nedovi J, et al. Anti-dsDNA, anti-nucleosome and anti$\mathrm{C} 1 \mathrm{q}$ antibodies as disease activity markers in patients with systemic lupus erythematosus. Serb Arch Med 2014; 142(7-8):431-6.

19. Gladman DD, Urowitz MB, Keystone EC. Serologically active clinically quiescent systemic lupus erythematosus: a discordance between clinical and serologic features. Am J Med 1979;66(2):210-5.

20. El-Shafey EM, El-Nagar GF, El-Bendary AS, Sabry AA, Selim AG. Serum soluble interleukin-2 receptor alpha in systemic lupus erythematosus. Iran J Kidney Dis 2008;2(2):80-85.

21. Pitashny M, Schwartz N, Qing X, Hojaili B, Aranow C, Mackay $\mathrm{M}$, et al. Urinary lipocalin 2 is associated with renal disease activity in human lupus nephritis. Arthritis Rheum 2007;56(6):1894-903.

22. Weening JJ, D'Agati VD, Schwartz MM, Seshan SV, Alpers CE, Appel GB, et al. The classification of glomerulonephritis in systemic lupus erythematosus revisited. J Am Soc Nephrol 2004;15(2):241-50.

23. Castro-Santana LE, Colón M, Molina MJ, Rodríguez VE, Mayor AM, Vilá LM. Efficacy of two cyclophosphamide regimens for the treatment of lupus nephritis in Puerto Ricans: low vs. standard dose. Ethn Dis 2010;20(1 Suppl 1):S1-121.

24. El-Shafey EM, Abdou SH, Shareef MM. Is mycophenolate mofetil superior to pulse intravenous cyclophosphamide for induction therapy of proliferative lupus nephritis in Egyptian patients? Clin Exp Nephrol 2010;14(3):21421.

25. Bao L, Cunningham PN, Quigg RJ. Complement in lupus nephritis: new perspectives. Kidney Dis 2015;1(2):91-9.

26. Rabrenovi V, Poskurica M, Kova evi Z, Neši V, Savin M, Miti B, et al. Treatment of lupus nephritis by mycophenolate mofetil. Kidney Blood Press Res 2010;33(4):297-303.

27. Gunes C, Keles M, Uyanik A, Cetinkaya R, Sari RA. Treatment Results of Patients with Lupus Nephritis: A Single Center's Experience. Eurasian J Med 2010;42(3):132.

28. Sharma M, Das HJ, Doley PK, Mahanta PJ. Clinical and histopathological profile of lupus nephritis and response to treatment with cyclophosphamide: A single center study. Saudi J Kidney Dis Transpl 2019;30(2):501-507.

29. Davas EM, Tsirogianni A, Kappou I, Karamitsos D, Economidou I, Dantis PC. Serum IL-6, TNF \pm , p55 srTNF \pm , p75 srTNF \pm , srIL-2 \pm levels and disease acitivity in systemic lupus erythematosus. Clin Rheumatol 1999;18(1):17-22. 